Article

\title{
Food-Energy Interactive Tradeoff Analysis of Sustainable Urban Plant Factory Production Systems
}

\author{
Li-Chun Huang ${ }^{1}$, Yu-Hui Chen ${ }^{2}$, Ya-Hui Chen ${ }^{3}$, Chi-Fang Wang ${ }^{4}$ and Ming-Che $\mathrm{Hu}^{4, *}$ \\ 1 Department of Bio-Industry Communication and Development, National Taiwan University, No. 1, Sec. 4, \\ Roosevelt Road, Taipei 10617, Taiwan; lihuang@ntu.edu.tw \\ 2 Department of Agricultural Economics, National Taiwan University, No. 1, Sec. 4, Roosevelt Road, \\ Taipei 10617, Taiwan; yhc@ntu.edu.tw \\ 3 Department of Business Administration, Hsuan Chuang University, No. 48, Hsuan Chuang Road, \\ Hsinchu City 300, Taiwan; yhchen558@hcu.edu.tw \\ 4 Department of Bioenvironmental Systems Engineering, National Taiwan University, No. 1, Sec. 4, \\ Roosevelt Road, Taipei 10617, Taiwan; cfwang@ntu.edu.tw \\ * Correspondence: mchu@ntu.edu.tw; Tel.: +886-2-33663448; Fax: +886-2-23635854
}

Received: 8 December 2017; Accepted: 4 February 2018; Published: 8 February 2018

\begin{abstract}
This research aims to analyze the food-energy interactive nexus of sustainable urban plant factory systems. Plant factory systems grow agricultural products within artificially controlled growing environment and multi-layer vertical growing systems. The system controls the supply of light, temperature, humidity, nutrition, water, and carbon dioxide for growing plants. Plant factories are able to produce consistent and high-quality agricultural products within less production space for urban areas. The production systems use less labor, pesticide, water, and nutrition. However, food production of plant factories has many challenges including higher energy demand, energy costs, and installation costs of artificially controlled technologies. In the research, stochastic optimization model and linear complementarity models are formulated to conduct optimal and equilibrium food-energy analysis of plant factory production. A case study of plant factories in the Taiwanese market is presented.
\end{abstract}

Keywords: food-energy tradeoff; plant factory; stochastic programming; market equilibrium

\section{Introduction}

The purpose of this research is to analyze the interactive tradeoff of food production and energy consumption nexus of plant factory systems. Stochastic optimization and linear complementarity problem (LCP) models of plant factories are established to investigate optimal strategies and competitive market equilibrium. Plant factories are advanced growing systems proposed for agricultural production. Plant factories provide an artificially controlled environment, including the control of temperature, humidity, light, carbon dioxide, cultivation solution, and water supply $[1,2]$. Multi-layer vertical growing systems are installed in plant factories in order to save growing space in urban areas. The average agricultural production per hectare (average yield) of plant factories is expected to be two to four times larger than production of an outdoor farm system. Plant factories use half artificial light and fully artificial light controlled systems. Half artificial light systems take advantage of sunlight in the daytime, while full light systems use complete artificial light. Hence, steady and high-quality plants can be produced in plant factories all year round. The technology for fully controlled plant factories in the cultivation of vegetables is developing rapidly in urban areas in Taiwan, Japan, and China, and can be applied to the cultivation of many different crops, such as herbs, fruits, vegetables, seedlings, and ornamental plants. Countries in Asia and the Middle East have successfully implemented plant factory systems. 
Cost reduction (less labor, nutrition, pesticide, and water demand), effective production, and better quality produce increase the incentives of food production of plant factories. However, intensive energy use, high energy costs, and high installation costs of plant factories are significant problems and need to be analyzed [3-7]. Energy demand, economic feasibility, and food-energy nexus are significant issues for food production industries [8,9]. Hence, the purpose of this research is to analyze food-energy nexus of the plant factory systems in the urban areas.

In the research, a two-stage stochastic programming model and an LCP models are established in order to discuss the food production and energy consumption of plant factories in the vegetable production market. The models are used to determine food-energy tradeoff in the Taiwanese market and a case study is conducted. The two-stage stochastic programming model contains two decision making stages for plant factory systems. The investment plan is determined in the first stage, and then the optimal operating strategies of food production and energy demand are decided in the second stage. Further, the LCP model is formulated to analyze plant factory production systems in the competitive market. An LCP model comprises non-negative constraints and complementarity conditions [10-13]. Note that all variables in the LCP model mentioned above are non-negative and paired with inequality constraints. Furthermore, a mixed LCP model contains both non-negative variables and unbounded variables. Unbounded variables are free variables without non-negativity constraints. More specifically, the mixed LCP has at least one pair of unbounded variables and its associated equality equations. By adding equality constraints and unbounded variables, the LCP model becomes a mixed LCP model. In this paper, an LCP model is established in order to simulate market competition among plant factories, which we then use to establish the market equilibrium of plant factory systems. The model is formulated on General Algebraic Modeling System (GAMS) and PATH solver is used to solve the problem. GAMS is an algebraic modeling language for solving large-size complex optimization models [14]. PATH is one of the most efficient solvers for solving LCP models [12]. Hence, the LCP model of plant factories is analyzed on GAMS and the market equilibrium solution is obtained using the PATH solver.

Interactive influence of food, energy and water are important for resources management [15-18]. Kan et al. [8] analyzed the energy-water-food nexus issue with improving water quantity simulation and forecasting. Schlor et al. [9] built the food, energy, and water nexus city index for measuring urban resilience. This research focuses on food-energy nexus of plant factory production system; previous studies related to food and energy tradeoff of plant factories are very limited. For example, previous studies have formulated optimization models and analyzed optimal operating strategies for a single plant factory only. Morimoto et al. [19] and Morimoto et al. [20] built an optimal management system with a Kalman filter in order to control the dynamic physiological processes of plants in a plant factory. In this system, the water status for plant growing is monitored by an automatic control system. Francisco and Ali [21] formulated a multi-objective programming model for a vegetable production system in the Philippines. This research considered four objectives, including minimizing price-induced risk, minimizing yield-induced risk, minimizing labor employment, and maximizing net return. In addition, they also discussed a tradeoff analysis for resource allocation. Caixeta-Filho et al. [22] established a decision support system in order to analyze the production planning and trade of lily flowers at the Jan de Wit Company. A linear programming model was formulated to maximize profit, subject to market sales, market requirements, production technology, bulb batch inventory, and the production capacity of a greenhouse. Company revenue grew by $26 \%$, costs decreased by $3.1 \%$, and the return on owner's equity increased by $7.4 \%$. Morimoto et al. [2] established a dynamic optimization model to reduce water loss in fruit during storage. In this research, they used the intelligent approach of neural networks in order to determine the water loss in tomatoes and developed a genetic algorithm to search for the optimal storage temperature. The results showed that heat stress, which refers to a sudden drop in temperature, efficiently decreases water loss and maintains the freshness of fruit. Canakci and Akinci [23] studied the economic performance of plant factories. They simulated and analyzed the energy use patterns of vegetable production in greenhouses. In addition, they measured the power consumed in greenhouse production 
and calculated the energy and economic performance of greenhouses. Finally, they conducted a case study of greenhouse farming in central Turkey. Van Straten et al. [24] developed an optimal control model for the greenhouse climate required for crop growth. They described the relationship between crop biomass growth and climate in a greenhouse production system using differential equations. Then, they used the model to determine optimal greenhouse control strategies with respect to temperature, moisture, and carbon dioxide. In addition, many researchers have studied and applied linear complementarity models in market competition problems. Hobbs [13] first established an LCP model to simulate Nash-Cournot competition in bilateral and POOLCO electric power markets. The model includes power generation firms, transmission grid owners, and market clearing conditions. In the model, a DC approximation is used to simplify Kirchhoff's laws of power transmission. Gabriel and Fuller [25] analyzed demand uncertainty in the electricity market. They formulated a stochastic complementarity problem considering several demand scenarios and proposed a Benders decomposition method in order to solve the model. The method established master and sub-problems within the model. The problems were solved iteratively until the solution was close to the point of convergence. In addition, previous studies have established optimization models for examining optimal operating strategies of plant production systems for plant factories. Economic analyses on plant factory production have also been undertaken. Further, deterministic and stochastic LCP models have been established for competitive markets in some studies. However, food-energy nexus of plant factory production using stochastic optimization and LCP competition has never been done.

The contribution of this research is to establish a stochastic programming and an LCP model to analyze the food and energy interactive nexus for plant factories in the market. The stochastic optimization and LCP models are formulated and solved on the GAMS system; then, price and quantity equilibrium solutions of the vegetable market can be determined. The models discuss food production, energy consumption, transportation, and market competition for plant factory production systems. Further, the market equilibrium solution provides interaction among factories in the market. A case study of plant factory production in the Taipei First Fruit and Vegetable Auction Market is conducted in the research. The remainder of this paper is organized in the following manner. In Section 2, the optimization and LCP competition models for food-energy tradeoff of plant factories are formulated and analyzed. Section 3 conducts a case study and discusses the results. Finally, the conclusions are presented in Section 4.

\section{Methodology}

In this section, we formulate a stochastic optimization model and an LCP competition model to analyze food-energy interactive nexus for plant factories production [13,25]. The two-stage stochastic programming model selects investment plans in the first stage and then determines optimal operating strategies for food production and energy demand in the second stage. The aim of the stochastic programming model is to develop an optimal management for food-energy interaction in plant factories. In addition, the LCP model analyzes food-energy interaction of market competition among plant factory markets. The market contains multiple plant production firms that behave competitively with respect to elastic market demand. Taking Karush-Kuhn-Tucker (KKT) optimality conditions of the competition model into account, an LCP model of the vegetable market is established and a market equilibrium solution is derived accordingly. The results display food-energy tradeoff in the equilibrium condition in which each firm has no economic incentive to deviate from current strategies.

For stochastic optimization, firm $f$ determines investment plans of factory $j$ for land, lighting, and other artificially controlled growing facility in the first stage. Then, in the second stage, plant $x p_{f j t s}{ }^{P T}$ is grown in plant factory $j$ and $x t_{f i j t}$ is delivered to vegetable market $i$ at time $t$ for uncertain scenarios. Accordingly, food production and energy consumption tradeoff is analyzed by the stochastic programming model for plant factories; the model is formulated as follows. The optimal operating strategies are determined by minimizing total cost of the production system. Total cost of plant factory is described in Equation (1). Equations (2)-(4) calculate the land, light, and nutrition demand. 
Capacity constraints are established in Equations (5)-(7). Equation (8) is transportation constraint and demand constraint is constructed in Equation (9). Electricity consumption and transportation fuel demand are estimated in Equation (10). Non-negativity constraints are displayed in Equation (11).

$$
\begin{aligned}
& \text { Min } \quad \Sigma_{j}\left(C T_{f j}{ }^{L D} \times c p_{f j}{ }^{L D}\right)+\Sigma_{j}\left(C T_{f j}{ }^{L T} \times c p_{f j}{ }^{L T}\right)+\Sigma_{j}\left(C T 1_{f j}{ }^{P T} \times c p_{f j}{ }^{P T}\right) \\
& +\Sigma_{s} P R_{f s} \times\left[\Sigma_{j t}\left(C T_{f j}{ }^{N T} \times x p_{f j t s}{ }^{N T}\right)+\Sigma_{j t}\left(C T 2_{f j}{ }^{P T} \times x p_{f j t s}{ }^{P T}\right)\right. \\
& \left.+\Sigma_{i j t}\left(C T_{f i j}^{T R} \times x t_{f i j t s}\right)\right] \\
& \text { s.t. } \quad R T_{f j t}{ }^{L D} \times x p_{f j t s}{ }^{P T}=x p_{f j t s}{ }^{L D} \\
& \forall j, t, s \\
& R T_{f j t}^{L T} \times x p_{f j t s}{ }^{P T}=x p_{f j t s}{ }^{L T} \\
& \forall j, t, s \\
& R T_{f j t}{ }^{N T} \times x p_{f j t s}{ }^{P T}=x p_{f j t s} N T \\
& \forall j, t, s \\
& x p_{f j t s}{ }^{L D} \leq c p_{f j}{ }^{L D} \\
& \forall j, t, s \\
& x p_{f j t s}{ }^{L T} \leq c p_{f j}^{L T} \\
& \forall j, t, s \\
& x p_{f j t s}{ }^{P T} \leq c p_{f j}{ }^{P T} \\
& \forall j, t, s \\
& x p_{f j t s}{ }^{P T} \geq \Sigma_{i} x t_{f i j t s} \\
& \forall j, t, s \\
& \Sigma_{j} x t_{\text {fijts }} \geq D M_{\text {fits }} \\
& \forall i, t, s \\
& \text { ele } e_{f}=\Sigma_{s} P R_{f s} \times\left[\Sigma_{j t}\left(\left(E L E_{f j}{ }^{L T}+E L E_{f j}{ }^{P T}\right) \times x p_{f j t s}{ }^{P T}\right)\right] \\
& g l_{f}=\Sigma_{s} P R_{f s} \times\left[\Sigma_{i j t}\left(G L_{f i}^{T R} \times x t_{f i j t s}\right)\right] \\
& c p_{f j}^{L D}, c p_{f j}^{L T}, c p_{f j}^{P T} \geq 0 \\
& x p_{f j t s}{ }^{L D}, x p_{f j t s} L T, x p_{f j t s}{ }^{N T}, x p_{f j t s} P T, x t_{f i j t s} \geq 0 \\
& \forall j \\
& \forall i, j, t, s
\end{aligned}
$$

Next, food-energy nexus of the LCP competition is analyzed as follows. In the vegetable market, plant production firm $f$ owns plant factory $j$ with production capacity $C A_{f j}$ and the firm grows plants $p r_{f j}$ in the plant factory. Further, energy demand for food production can be calculated based on ele $e_{f}=\Sigma_{i j}\left(\left(E L E_{f j}{ }^{L T}+E L E_{f j}{ }^{P T}\right) \times p r_{f j}\right)$ and $g l_{f}=\Sigma_{i j}\left(G L_{f i}{ }^{T R} \times t r_{f i j}\right)$. The production cost in plant factory $j$ of firm $f$ is $P C_{f j}$. Vegetable $t r_{f i j}$, grown in the factory $j$ by firm $f$, is delivered to vegetable market $i$ and the transportation cost is $T C_{f i j}$. Then vegetable $s a_{f i}$ is provided by firm $f$ and sold in market $i$. The demand in the vegetable market is a function of price. This research uses inverse demand curves to calculate the price based on the total vegetable sales in the markets. The inverse demand curve of market $i$ has a positive price intercept $P I_{i}$ and positive quantity intercept $Q I_{i}$. Hence, the price is $\left(P I_{i}-\left(P I_{i} / Q I_{i}\right) \times\left(\Sigma_{g} s a_{g i}\right)\right)$ and the revenue of firm $f$ is $\left(P I_{i}-\left(P I_{i} / Q I_{i}\right) \times\left(\Sigma_{g} s a_{g i}\right)\right) \times s a_{f i}$ in market $i$. Deducting production cost of $P C_{f j} \times p r_{f j}$ and transportation cost of $T C_{f i j} \times t r_{f i j}$, yields Equation (12), which is a convex function that calculates the total profit of firm $\mathrm{f}$. Sale and transportation quantity are computed in Equations (13) and (14). Equation (15) lists the production capacity constraints and Equation (16) displays the non-negativity constraints. In addition, $\alpha_{f i}, \beta_{f j}$, and $\gamma_{f j}$ are dual (shadow) variables of Equations (13)-(15). In the model, plant production firms behave non-cooperatively in a quantity competition market. Subject to the constraints of Equations (13)-(16), firm f seeks optimal production, transportation, and selling strategies by maximizing firm profit in Equation (12). The profit maximizing problem of plant factory $f$ is established in Equations (12)-(16).

$$
\begin{aligned}
& \operatorname{Max} \quad \Sigma_{i}\left[\left(P I_{i}-\left(P I_{i} / Q I_{i}\right) \times\left(\Sigma_{g} s a_{g i}\right)\right) \times s a_{f i}\right] \\
& -\Sigma_{i j}\left[T C_{f i j} \times t r_{f i j}\right]-\Sigma_{j}\left[P C_{f j} \times p r_{f j}\right]
\end{aligned}
$$

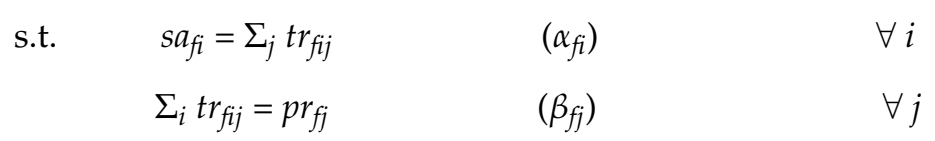




$$
\begin{array}{lll}
p r_{f j} \leq C A_{f j} & \left(\gamma_{f j}\right) & \forall j \\
s a_{f i}, t r_{f i j}, p r_{f j} \geq 0 & & \forall i, j
\end{array}
$$

Note that the profit maximizing problem of firm $\mathrm{f}$ in Equations (12)-(16) is a quadratic programming model with a convex objective function and linear constraints. The KKT conditions are necessary and sufficient optimality conditions for the profit maximizing problem $[10,13,25]$. The KKT conditions of all vegetable production firms in the market are derived and collected in Equations (17)-(22). Since Equations (13) and (14) are equality constraints, the corresponding dual variables $\left(\alpha_{f i}\right.$ and $\left.\beta_{f j}\right)$ are unrestricted in Equations (17) and (18). Otherwise, the dual variables are non-negative and the associated KKT conditions are derived in Equations (19)-(22). Collecting the KKT conditions yields an LCP model in Equations (17)-(22). Then, the LCP model is formulated on GAMS and solved using the PATH solver.

The KKT conditions of firm $f$ for $\alpha_{f i}$ are

$$
\left[s a_{f i}-\Sigma_{j} t_{f i j}\right]=0 . \quad \forall i
$$

The KKT conditions of firm $f$ for $\beta_{f j}$ are

$$
\left[\Sigma_{i} \operatorname{tr}_{f i j}-p r_{f j}\right]=0 . \quad \forall j
$$

The KKT conditions of firm $f$ for $\gamma_{f j} \geq 0$ are

$$
\begin{array}{lc}
{\left[-p r_{f j}+C A_{f j}\right] \geq 0 \text { and }} & \forall j \\
\gamma_{f j} \times\left[-p r_{f j}+C A_{f j}\right]=0 . & \forall j
\end{array}
$$

The KKT conditions of firm $f$ for $s a_{f i} \geq 0$ are

$$
\begin{array}{ll}
{\left[\alpha_{f i}-P I_{i}+\left(P I_{i} / Q I_{i}\right) \times\left(\Sigma_{g} s a_{g i}+s a_{f i}\right)\right] \geq 0 \text { and }} & \forall i \\
s a_{f i} \times\left[\alpha_{f i}-P I_{i}+\left(P I_{i} / Q I_{i}\right) \times\left(\Sigma_{g} s a_{g i}+s a_{f i}\right)\right]=0 . & \forall i
\end{array}
$$

The KKT conditions of firm $f$ for $\operatorname{tr}_{f i j} \geq 0$ are

$$
\begin{array}{ll}
{\left[-\alpha_{f i}+\beta_{f j}+T C_{f i j}\right] \geq 0 \text { and }} & \forall i, j \\
\operatorname{tr}_{f i j} \times\left[-\alpha_{f i}+\beta_{f j}+T C_{f i j}\right]=0 . & \forall i, j
\end{array}
$$

The KKT conditions of firm $f$ for $p r_{f j} \geq 0$ are

$$
\begin{array}{ll}
{\left[-\beta_{f j}+\gamma_{f j}+P C_{f j}\right] \geq 0 \text { and }} & \forall j \\
p r_{f j} \times\left[-\beta_{f j}+\gamma_{f j}+P C_{f j}\right]=0 . & \forall j
\end{array}
$$

In order to investigate the impact of arbitrage behavior in the market, an LCP competition model with arbitrage is established. The arbitrage in market $i$ is $a r_{i}$ and total sales becomes $\left(\Sigma_{g} s a_{g i}+a r_{i}\right)$. The market price and objective function of the profit maximizing problem for firm $\mathrm{f}$ are modified and established in Equation (23)-(27). In order to analyze the LCP competition model with arbitrage, an additional profit maximizing problem for an arbitrager is established in Equations (28) and (29). Equation (28) computes the total profit of arbitrage and Equation (29) is the mass balance constraint for vegetable arbitrage. Hence, the LCP model includes firm optimization model in Equations (23)-(27) 
and arbitrage model in Equations (28) and (29). Solving the profit maximizing problems for firms and arbitragers simultaneously in Equations (23)-(29) quantifies arbitrage behavior in the market.

$$
\begin{aligned}
& \text { Max } \quad \Sigma_{i}\left[\left(P I_{i}-\left(P I_{i} / Q I_{i}\right) \times\left(\Sigma_{g} s a_{g i}+a r_{i}\right)\right) \times s a_{f i}\right] \\
& -\Sigma_{i j}\left[T C_{f i j} \times t r_{f i j}\right]-\Sigma_{j}\left[P C_{f j} \times p r_{f j}\right] \\
& \text { s.t. } \\
& \begin{array}{lcc}
s a_{f i}=\Sigma_{j} t r_{f i j} & \left(\alpha_{f i}\right) & \forall \\
\Sigma_{i} t r_{f i j}=p r_{f j} & \left(\beta_{f j}\right) & \forall j \\
p r_{f j} \leq C A_{f j} & \left(\gamma_{f j}\right) & \forall j
\end{array} \\
& s a_{f i}, t r_{f i j}, p r_{f j} \geq 0 \quad \forall i, j \\
& \text { Max } \quad \Sigma_{i}\left[\left(P I_{i}-\left(P I_{i} / Q I_{i}\right) \times\left(\Sigma_{g} s a_{g i}+a r_{i}\right)\right) \times a r_{i}\right]
\end{aligned}
$$

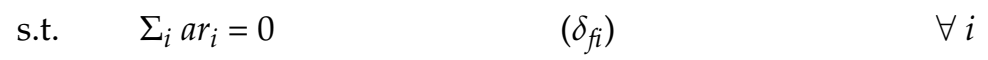

\section{Results and Discussion}

This section begins by conducting a case study of plant factory competition in the Taipei First Fruits and Vegetables Auction Market; accordingly, the nexus of food production and energy consumption of plant factories is examined. The market demand curve of a plant factory in the Taipei vegetables market is derived in the following manner. First, suppose current consumers of organic vegetables are the potential buyers for vegetables produced by the plant factory in the market. According our survey, the average price of organic vegetables is approximately 150-220 NTD/ $\mathrm{kg}$ in the market (NTD is the new Taiwan dollar; one USD is approximately 29-32 NTD). Next, the average organic vegetable consumptions are $64.8 \mathrm{~kg} /$ household and $84.8 \mathrm{~kg} /$ household annually in Taipei city and New Taipei city, respectively. In addition, the number of households are 948,613 and 1,337,172 in Taipei city and New Taipei city, respectively. Hence, the combined annual consumption level of organic vegetables is approximately $174,862,308 \mathrm{~kg}$ in Taipei city and New Taipei city. The plant factory industry in Taiwan has stated a goal of replacing $25 \%$ of the organic vegetable consumption for industry development. In order to liken this study to the empirical status of the industry, the model is run under the assumption that plant factories supply $25 \%$ of organic vegetable consumption. Then, the total vegetable demand of plant factories is $43,715,577 \mathrm{~kg}$ in Taipei and New Taipei. The price intercept and quantity intercept of the demand function are 1150 NTD and $5.0273 \times 10^{7} \mathrm{~kg}$, respectively. Then, linear demand functions of plant factories are established in Equations (30) and (31).

$$
\begin{aligned}
& P=1150-\left(\frac{1150}{5.0273 \times 10^{7}}\right) \times Q \\
& P=1150-\left(2.2875 \times 10^{-5}\right) \times Q
\end{aligned}
$$

where $P(\mathrm{NTD} / \mathrm{kg})$ represents vegetable price and $Q(\mathrm{~kg})$ is the amount of vegetables provided by the plant factories.

As a result of agricultural production in Taiwan typically originating from small farms, most growers distribute their fresh vegetables to the wholesale market via the transportation system, the so-called co-transportation system, in order to reduce transportation costs. In a co-transportation system, the administration office, usually managed by farmers association or by farmers co-production groups, gather vegetables from many vegetable growers up to a certain amount and then transport these vegetables to the wholesale market. In a co-transportation system, numerous farmers share the same transportation instruments and thus the transportation cost is reduced for each individual farmer.

In this study, we estimated the transportation cost and fuel consumption for plant factories in different geographic regions. Therefore, we contacted the farmers associations located at the main vegetable production regions of Taiwan in order to collect data on price rates to transport fresh 
vegetables to the Taipei First Fruits and Vegetables Auction Market, the largest auction market for fresh vegetables and fruits in Taiwan. According to the information collected from the farmers associations, the transportation rate is mostly standardized according to the distance from the administration districts, rather than factory locations. Consequently, we called the farmers' associations located at the main vegetable production regions of Taiwan to obtain the empirical transportation rate data. The transportation rates reported from each farmer association are listed in Table 1.

Table 1. Location and transportation costs of Farmers' Associations in Taiwan.

\begin{tabular}{|c|c|c|}
\hline Region & Location of Farmers' Associations & Transportation Rate (NTD/kg) \\
\hline Northern Taiwan Region & Farmers' Association of Qionglin in Hsinchu County & 1.0 \\
\hline \multirow{3}{*}{ Central Taiwan Region } & Farmers' Association of Ren-Ay in Nantou County & 1.7 \\
\hline & Farmers' Association of Guoxing in Nantou County & 1.5 \\
\hline & Farmers' Association of Yongjing in Changhua County & 1.4 \\
\hline \multirow{4}{*}{ Southern Taiwan Region } & Farmers' Association of Xuejiu in Tainan & 1.8 \\
\hline & Farmers' Association of Zuozhen in Tainan & 1.8 \\
\hline & Farmers' Association of Fangliao in Pingtung & 1.7 \\
\hline & Farmers' Association of Manzhou in Pingtung & 1.6 \\
\hline Eastern Taiwan Region & Farmers' Association of Ji-An in Hualien County & 2.3 \\
\hline
\end{tabular}

Table 2 shows the variable transportation costs for different plant factories delivering to the Taipei First Fruits and Vegetables Auction Market. The lowest cost is $0.65 \mathrm{NTD} / \mathrm{kg}$, transported from Keelong, Taipei, and Taoyuan to the market place in Taipei. The costs increase to 3.70, 4.00, and 4.20 NTD/kg for plant factories located in Tainan, Kaohsiung, and Pingtung of Southern Taiwan, respectively. The costs delivered from Eastern Taiwan are 1.90, 3.25, and 5.70 NTD/kg for Yilan, Hualien, and Taitung, respectively. The transportation costs and energy demand of the vegetable market is simulated and measured in Table 3. The results show that installing plant factories in Northern Taiwan (Keelung, Taipei, Taoyuan, and Zhongli) produces around 15,290 ton vegetable / firm/year with fuel consumption of 1.8-3.2 thousand GJ/firm/year. Plant factories generate 15,280-15,260 ton vegetable / firm/year (with transportation fuel of 3.5-10.0 thousand GJ/firm/year) in Central Taiwan; 15,260-15,240 ton vegetable / firm/year (with transportation fuel of 11.9-16.9 thousand GJ/firm/year) in Southern Taiwan. In Eastern Taiwan, the food production ranges from 15,250-15,270 ton vegetable / firm/year (with transportation fuel of 3.1-23.3 thousand GJ/firm/year).

Table 2. Transportation costs for different plant factory locations.

\begin{tabular}{cccc}
\hline $\begin{array}{c}\text { Location of Plant } \\
\text { Factory }\end{array}$ & $\begin{array}{c}\text { Transportation Cost to } \\
\text { Taipei }\end{array}$ & $\begin{array}{c}\text { Location of Plant } \\
\text { Factory }\end{array}$ & $\begin{array}{c}\text { Transportation Cost to } \\
\text { Taipei }\end{array}$ \\
\cline { 2 - 3 } (NTD/kg) & & Yunlin & (NTD/kg) \\
\hline Hualien & 3.25 & Changhua & 2.75 \\
Yilan & 1.90 & Chiayi & 2.55 \\
Keelung & 0.65 & Xinying & 2.95 \\
Taipei & 0.65 & Madou & 3.25 \\
Taoyuan & 0.65 & Tainan & 3.50 \\
Zhongli & 0.95 & Kaohsiung & 3.70 \\
Hsinchu & 1.35 & Pingtung & 4.00 \\
Miaoli & 1.55 & Taitung & 4.20 \\
Taichung & 2.25 & & 5.70 \\
Nantou & 2.55 & & \\
\hline
\end{tabular}


Table 3. The transportation costs and fuel consumption on equilibrium in the vegetable market: a two-firm case.

\begin{tabular}{ccccccc}
\hline $\begin{array}{c}\text { Location of } \\
\text { Plant }\end{array}$ & $\begin{array}{c}\text { Food Sale } \\
\text { (kg/Firm/Year) }\end{array}$ & $\begin{array}{c}\text { Transportation } \\
\text { Fuel Demand } \\
\text { (GJ/Firm/Year) }\end{array}$ & $\begin{array}{c}\text { Price } \\
\text { (NTD/kg/Year) }\end{array}$ & $\begin{array}{c}\text { Production Cost } \\
\text { (NTD/Firm/Year) }\end{array}$ & $\begin{array}{c}\text { Transportation } \\
\text { Cost } \\
\text { (NTD/Firm/Year) }\end{array}$ & $\begin{array}{c}\text { Profit } \\
\text { (NTD/Firm/Year) }\end{array}$ \\
\hline $\begin{array}{c}\text { Hualien } \\
\text { Yilan }\end{array}$ & $15,253,093$ & 8054 & 452.17 & $1,525,309,000$ & $49,572,554$ & $5,322,059,000$ \\
Taoyuan & $15,272,765$ & 3161 & 451.27 & $1,527,277,000$ & $29,018,254$ & $5,335,795,000$ \\
Zhongli & $15,290,980$ & 1835 & 450.43 & $1,529,098,000$ & $9,939,137$ & $5,348,530,000$ \\
Hsinchu & $15,286,609$ & 2201 & 450.63 & $1,528,661,000$ & $14,522,278$ & $5,345,472,000$ \\
Miaoli & $15,280,780$ & 3530 & 450.90 & $1,528,078,000$ & $20,629,053$ & $5,341,397,000$ \\
Taichung & $15,277,866$ & 4813 & 451.03 & $1,527,787,000$ & $23,680,692$ & $5,339,359,000$ \\
Nantou & $15,267,665$ & 7328 & 451.50 & $1,526,767,000$ & $34,352,247$ & $5,332,232,000$ \\
Yunlin & $15,263,294$ & 10,074 & 451.70 & $1,526,329,000$ & $38,921,399$ & $5,329,179,000$ \\
Changhua & $15,260,379$ & 9935 & 451.83 & $1,526,038,000$ & $41,966,043$ & $5,327,144,000$ \\
Chiayi & $15,263,294$ & 7830 & 451.70 & $1,526,329,000$ & $38,921,399$ & $5,329,179,000$ \\
Xinying & $15,257,465$ & 11,855 & 451.97 & $1,525,746,000$ & $45,009,522$ & $5,325,110,000$ \\
Madou & $15,253,093$ & 11,989 & 452.17 & $1,525,309,000$ & $49,572,554$ & $5,322,059,000$ \\
Tainan & $15,246,450$ & 12,627 & 452.33 & $1,524,945,000$ & $53,373,077$ & $5,319,517,000$ \\
Kaohsiung & $15,242,165$ & 13,813 & 452.47 & $1,524,654,000$ & $56,412,183$ & $5,317,484,000$ \\
Pingtung & $15,239,250$ & 15,684 & 452.67 & $1,524,216,000$ & $60,968,658$ & $5,314,435,000$ \\
Taitung & $15,217,392$ & 16,916 & 452.80 & $1,523,925,000$ & $64,004,851$ & $5,312,403,000$ \\
\hline
\end{tabular}

In Table 4, the case study also analyzes the food production, electricity consumption of lighting and environmental control, transportation energy consumption, market price, firm sales, revenue, costs, and benefits for different numbers of symmetric firms in the Taiwanese vegetable market. The results show increasing the number of firms from two to ten amplifies the competition in the market. In this case, the equilibrium food sales quantity reduces from $15,300,452 \mathrm{~kg} /$ firm/year to 4,172,851 kg/firm/year for two-firm and ten firm cases, respectively. Electricity consumption of plant factories includes lighting, air conditioning, pumping, and other environmental control. Electricity demand is approximately $10-17.5 \mathrm{kWh} / \mathrm{kg}[26,27]$ for plant factories production. Then, electricity consumption of lighting and environmental control are 963,928 GJ/firm/year for two-firm case and 262,890 GJ/firm/year for ten firm case. Further, transportation energy demand decreases from $4590 \mathrm{GJ} /$ firm/year to $1252 \mathrm{GJ} /$ firm/year, while the equilibrium price reduces from $450 \mathrm{NTD} / \mathrm{kg}$ to $195.45 \mathrm{NTD} / \mathrm{kg}$. Revenue and profit of a single firm in the two-firm case are 6,885,203,000 NTD/firm/year and 5,355,158,000 NTD/firm/year, respectively. In the ten-firm case, the revenue and profit reduce to $815,602,600 \mathrm{NTD} /$ firm/year and 398,317,600 NTD/firm/year, respectively.

Table 4. Results of different number of firms in the vegetable market.

\begin{tabular}{cccccc}
\hline $\begin{array}{c}\text { Number of } \\
\text { Firms }\end{array}$ & Vegetable Sale & $\begin{array}{c}\text { Electricity of Lighting, } \\
\text { Environmental Control }\end{array}$ & $\begin{array}{c}\text { Transportation } \\
\text { Fuel Demand }\end{array}$ & \multicolumn{2}{c}{ Price } \\
\cline { 2 - 6 } & $\mathbf{( k g / F i r m / Y e a r )}$ & (GJ/Firm/Year) & (GJ/Firm/Year) & (NTD/kg/Year) & (NTD/Firm/Year) \\
\hline 2 & $15,300,452$ & 963,928 & 4590 & 450.00 & $5,355,158,000$ \\
3 & $11,475,339$ & 722,946 & 3443 & 362.50 & $3,012,276,000$ \\
4 & $9,180,271$ & 578,357 & 2754 & 310.00 & $1,927,857,000$ \\
5 & $7,650,226$ & 481,964 & 2295 & 275.00 & $1,338,790,000$ \\
6 & $6,557,337$ & 413,112 & 1967 & 250.00 & $983,600,500$ \\
7 & $5,737,669$ & 361,473 & 1721 & 231.25 & $753,069,100$ \\
8 & $5,100,151$ & 321,309 & 1530 & 216.67 & $595,017,600$ \\
9 & $4,590,136$ & 289,179 & 1377 & 205.00 & $481,964,200$ \\
10 & $4,172,851$ & 262,890 & 1252 & 195.45 & $398,317,600$ \\
\hline
\end{tabular}

In order to examine the payback period of plant factory investment, a uniform series profit is related to present investment in the following manner. Given a series of annually uniform profits, we can express the present equivalent value in Equation (32).

$$
P=A \times\left[(1+i)^{N}-1\right] /\left[i \times(1+i)^{N}\right],
$$


where $P, A, i$, and $\mathrm{N}$ are the present capital investment, annual income, interest rate, and payback period, respectively. Rearranging Equation (32) yields the payback period in Equation (33).

$$
N=\log _{(1+i)}[A /(A-P \times i)]
$$

The average fixed cost is estimated at approximately 3,346,696,362 NTD and the annual profit for each firm is calculated in Table 4 . The investment payback periods for scenarios with different interest rates and number of firms are compared in Table 5. The payback period ranges from 0.6 years to 10.5 years under interest rates of $0 \%, 1 \%, 2 \%, 3 \%$, and $4 \%$. Increasing the number of firms intensifies the market competition, cuts profits, and reduces the investment payback period. As interest rates rise, the present equivalence of annual income declines and the payback period is prolonged.

Table 5. Payback periods of different number of firms in the vegetable market (years).

\begin{tabular}{cccccc}
\hline \multirow{2}{*}{ Number of Firms } & \multicolumn{5}{c}{ Interest Rate } \\
\cline { 2 - 6 } & $\mathbf{0 \%}$ & $\mathbf{1 \%}$ & $\mathbf{2 \%}$ & $\mathbf{3 \%}$ & $\mathbf{4 \%}$ \\
\hline 2 & 0.6256 & 0.6307 & 0.6358 & 0.6409 & 0.6461 \\
3 & 1.1121 & 1.1239 & 1.1359 & 1.1480 & 1.1602 \\
4 & 1.7377 & 1.7617 & 1.7862 & 1.8112 & 1.8368 \\
5 & 2.5023 & 2.5467 & 2.5926 & 2.6400 & 2.6889 \\
6 & 3.4059 & 3.4825 & 3.5626 & 3.6463 & 3.7341 \\
7 & 4.4485 & 4.5732 & 4.7054 & 4.8459 & 4.9958 \\
8 & 5.6301 & 5.8237 & 6.0326 & 6.2590 & 6.5056 \\
9 & 6.9507 & 7.2401 & 7.5585 & 7.9114 & 8.3061 \\
10 & 8.4104 & 8.8291 & 9.3004 & 9.8369 & 10.4562 \\
\hline
\end{tabular}

\section{Conclusions}

Interactive food-energy nexus of plant factory production systems is analyzed. Plant factory systems provide stable and better quality vegetables or flowers by controlling growing conditions. However, the systems have high energy consumption (of lighting, air conditioning, and other environmental control) compared with outdoor and un-control farming systems. These plant factory systems are able to supply in accordance with market demand all year round at competitive prices. Plant factories are indoor production systems with artificially controlled environments. These factories control light, temperature, humidity, carbon dioxide concentration, water, nutrition solution, and so on. They recycle water and nutrition and use no pesticide and less labor.

This research has formulated uncertain profit maximizing problems for plant factories; then two-stage stochastic investment and food-energy tradeoff of plant factory production was determined. Next, derived and combining KKT optimality conditions, an LCP model was established in order to examine the food-energy nexus of plant factories in the competitive vegetable market. Moreover, a case study of the Taipei First Fruits and Vegetables Auction Market was performed. The model developed here considers the vegetable production, energy demand of plant factory production, the transportation costs and energy consumption from factories to markets, and the elastic demand function of the Taipei First Fruits and Vegetables Auction Market. The results show that food production range from 4.2 to 15.3 million $\mathrm{kg} /$ firm/year (with transportation fuel demand of 1.3 and 4.6 thousand GJ/firm/year) in the Taipei First Fruits and Vegetables Auction Market. The payback periods are $0.6-8.4$ years, based on a $0 \%$ interest rate, but increase to $0.6-10.5$ years when the interest rate increases to $4 \%$. Furthermore, as more firms enter the industry, the payback periods become more sensitive to a change in interest rate. For example, if there are two to six firms in the plant industry, the difference in payback periods ranges from $0.02-0.33$ years as the interest rate changes from $0-4 \%$. For nine firms, the payback period increases to more than a year (1.36 years) and for ten firms, to 2.04 years as the interest rate changes from $0-4 \%$. 
The focus of this paper was on the stochastic optimal programming model and LCP model of plant factories in the Taipei First Fruits and Vegetables Auction Market. The models provided innovative methodology, framework, and a case study to analyze food-energy tradeoff of plant factory production in competitive vegetable markets. The research framework and models can be applied to any other resources tradeoff analysis and food production markets. Future studies include simulation of asymmetric firm competition in food markets, locational food production and differentiate energy demand, analysis of multiple markets and multiple production systems of plant factories, and tradeoff of transportation energy and climate related production energy. Furthermore, conducting an uncertainty analysis and establishing a stochastic food-energy analysis of the LCP model are potential extensions of this research.

Acknowledgments: The authors would like to thank the anonymous referees and editors for their thoughtful comments and suggestions. The authors are responsible for the accuracy of the information presented in this paper and for all opinions expressed herein. This research was funded by the National Taiwan University under Grant NTU-CCP-106R891007 and the Ministry of Science and Technology of Taiwan under Grant MOST-106-2627-M-002-027.

Author Contributions: Ming-Che Hu, Li-Chun Huang, and Yu-Hui Chen conceived and designed this research; Ming-Che Hu, Ya-Hui Chen, and Chi-Fang Wang collected the data; Ming-Che Hu, Ya-Hui Chen, and Chi-Fang Wang analyzed the data; Ming-Che Hu, Li-Chun Huang contributed analysis tools; Ming-Che Hu, Li-Chun Huang, and Yu-Hui Chen wrote the paper.

Conflicts of Interest: The authors declare no conflicts of interest.

\section{Nomenclature}

In this paper, indices and decision variables use lowercase letters. Uppercase letters indicate coefficients. The indices, coefficients, and decision variables are listed below, including the definitions and units.

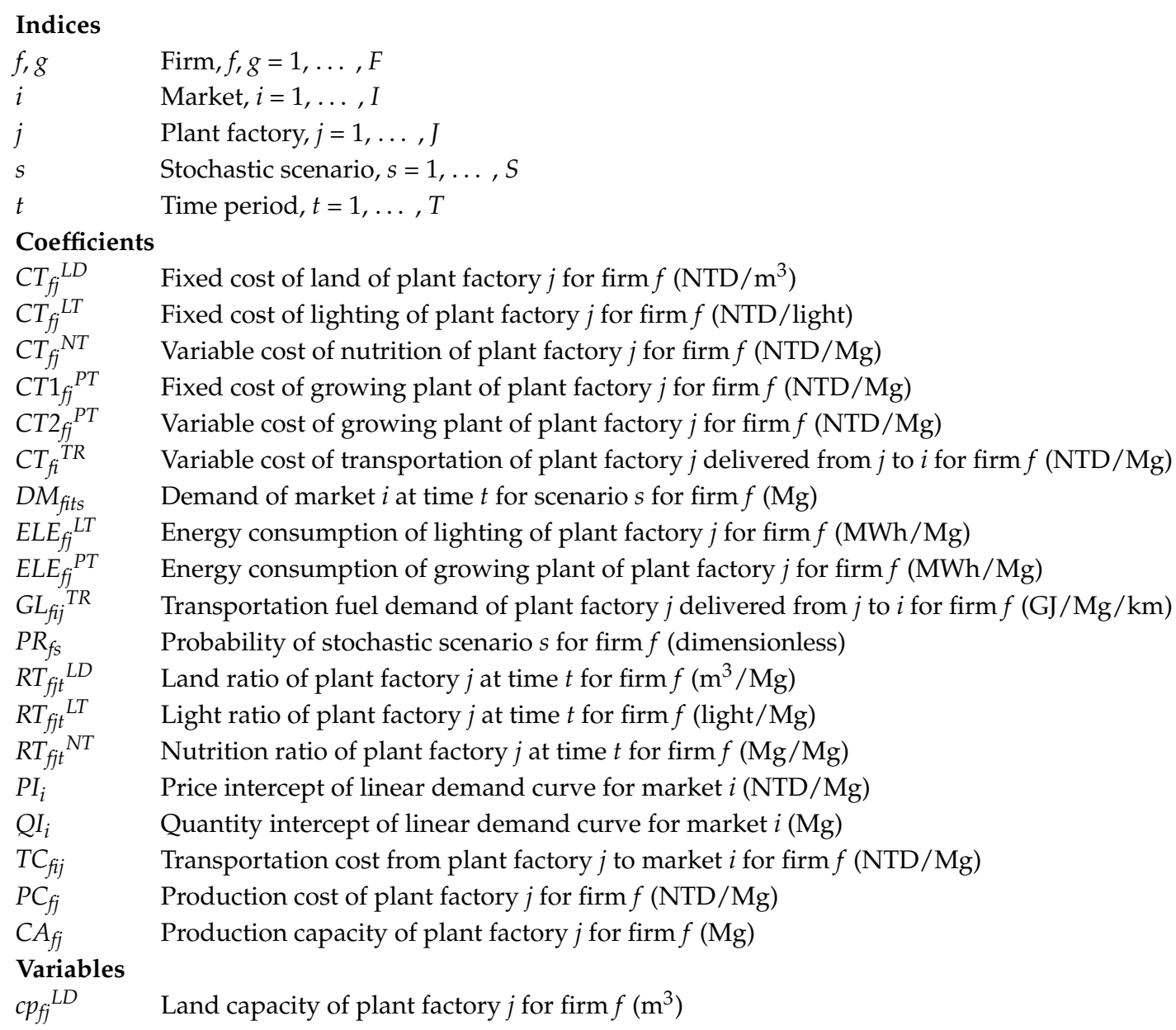




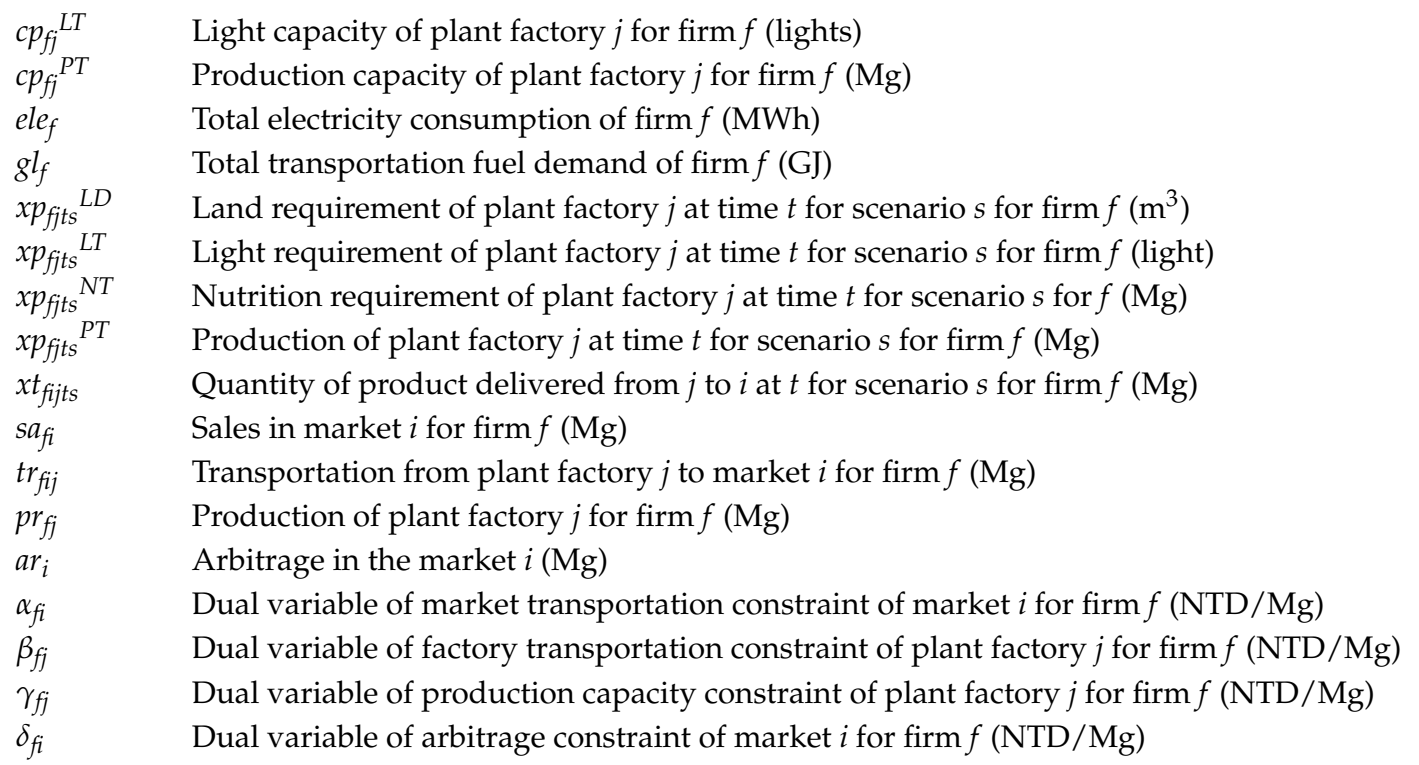

\section{References}

1. Seginer, I.; Ioslovich, I. Optimal spacing and cultivation intensity for an industrialized crop production system. Agric. Syst. 1999, 62, 143-157. [CrossRef]

2. Morimoto, T.; Tu, K.; Hatou, K.; Hashimoto, Y. Dynamic optimization using neural networks and genetic algorithms for tomato cool storage to minimize water loss. Trans. ASABE 2003, 46, 1151-1159. [CrossRef]

3. Kruseman, G.; Bade, J. Agrarian policies for sustainable land use: Bio-economic modeling to assess the effectiveness of policy instruments. Agric. Syst. 1998, 58, 465-481. [CrossRef]

4. Lopez Cruz, I.L.; van Willigenburg, L.G.; van Straten, G. Optimal control of nitrate in lettuce by a hybrid approach: Differential evolution and adjustable control weight gradient algorithms. Comput. Electron. Agric. 2003, 40, 179-197. [CrossRef]

5. Tzilivakis, J.; Warner, D.J.; May, M.; Lewis, K.A.; Jaggard, K. An assessment of the energy inputs and greenhouse gas emissions in sugar beet (Beta vulgaris) production in the UK. Agric. Syst. 2005, 85, 101-119. [CrossRef]

6. Pandey, C.B.; Rai, R.B.; Singh, L.; Singh, A.K. Homegardens of Andaman and Nicobar, India. Agric. Syst. 2007, 92, 1-22. [CrossRef]

7. McGuire, S.J. Path-dependency in plant breeding: Challenges facing participatory reforms in the Ethiopian Sorghum Improvement Program. Agric. Syst. 2008, 96, 139-149. [CrossRef]

8. Kan, G.; Zhang, M.; Liang, K.; Wang, H.; Jiang, Y.; Li, J.; Ding, L.; He, X.; Hong, Y.; Zuo, D.; et al. Improving Water quantity simulation \& forecasting to solve the energy-water-food nexus issue by using heterogeneous computing accelerated global optimization method. Appl. Energy 2018, 210, 420-433. [CrossRef]

9. Schlor, H.; Venghaus, S.; Hake, J.-F. The FEW-Nexus city index-Measuring urban resilience. Appl. Energy 2018, 210, 382-392. [CrossRef]

10. Cottle, R.W.; Pang, J.S.; Stone, R.E. The Linear Complementarity Problem; Academic Press: New York, NY, USA, 1992.

11. Mas-Colell, A.; Whinston, M.D.; Green, J.R. Microeconomic Theory; Oxford University Press: New York, NY, USA, 1995.

12. Ferris, M.C.; Munson, T.S. GAMS/PATH User Guide. Version 4.3. 2000. Available online: https://www. gams.com/latest/docs/S_MAIN.html (accessed on 7 February 2018).

13. Hobbs, B.F. Linear complementarity models of Nash-Cournot competition in bilateral and POOLCO power markets. IEEE Trans. Power Syst. 2001, 16, 194-202. [CrossRef]

14. Rosenthal, R.E. GAMS: A User's Guide. 2008. Available online: https://www.gams.com/latest/docs/UG_ MAIN.html (accessed on 7 February 2018).

15. Rodias, E.; Berruto, R.; Busato, P.; Bochtis, D.; Sørensen, C.G.; Zhou, K. Energy Savings from Optimised In-Field Route Planning for Agricultural Machinery. Sustainability 2017, 9, 1956. [CrossRef] 
16. White, D.D.; Jones, J.L.; Maciejewski, R.; Aggarwal, R.; Mascaro, G. Stakeholder analysis for the Food-Energy-Water nexus in Phoenix, Arizona: Implications for nexus governance. Sustainability 2017, 9, 2204. [CrossRef]

17. Yang, S.; Xiao, Y.; Zheng, Y.; Liu, Y. The Green Supply Chain Design and Marketing Strategy for Perishable Food Based on Temperature Control. Sustainability 2017, 9, 1511. [CrossRef]

18. Zhao, Q.R.; Chen, Q.H.; Liu, Q.M.; Tian, G.Q.; Chu, X.L.; Xiao, Y.T. Saving forests through development? Fuelwood consumption and the energy-ladder hypothesis in rural Southern China. Transform. Bus. Econ. 2017, 16, 199-219.

19. Morimoto, T.; Torii, T.; Hashimoto, Y. Optimal control of physiological processes of plants in a green plant factory. Control Eng. Prac. 1995, 3, 505-511. [CrossRef]

20. Morimoto, T.; Purwanto, W.; Suzuki, J.; Hashimoto, Y. Optimization of heat treatment for fruit during storage using neural networks and genetic algorithms. Comput. Electron. Agric. 1997, 19, 87-101. [CrossRef]

21. Francisco, S.R.; Ali, M. Resource allocation tradeoffs in Manila's peri-urban vegetable production systems: An application of multiple objective programming. Agric. Syst. 2006, 87, 147-168. [CrossRef]

22. Caixeta-Filho, J.V.; van Swaay-Neto, J.M.; de Pa'dua Wagemaker, A. Optimization of the production planning and trade of lily flowers at Jan de Wit Company. Interfaces 2002, 32, 35-46. [CrossRef]

23. Canakci, M.; Akinci, I. Energy use pattern analyses of greenhouse vegetable production. Energy 2006, 31, 1243-1256. [CrossRef]

24. Van Straten, G.; Challa, H.; Buwalda, F. Towards user accepted optimal control of greenhouse climate. Comput. Electron. Agric. 2000, 26, 221-238. [CrossRef]

25. Gabriel, S.A.; Fuller, J.D. A Benders decomposition method for solving stochastic complementarity problems with an application in energy. Comput. Econ. 2010, 35, 301-329. [CrossRef]

26. Perez, V.M. Study of the Sustainbility Issues of Food Production Using Vertical Farm Methods in an Urban Environment within the State of Indiana. Master's Thesis, Purdue University, West Lafayette, IN, USA, 2014.

27. Kozai, T.; Niu, G.; Takagaki, M. Plant Factory: An Indoor Vertical Farming System for Efficient Quality Food Production; Academic Press: Cambridge, MA, USA, 2015.

(C) 2018 by the authors. Licensee MDPI, Basel, Switzerland. This article is an open access article distributed under the terms and conditions of the Creative Commons Attribution (CC BY) license (http:/ / creativecommons.org/licenses/by/4.0/). 